\title{
Synthesis and Evaluation of New Brominated Azaflavones and Azaflavanone Derivatives as Cytotoxic agents against Breast Cancer Cell Line (MCF-7)
}

\author{
Srujana Muthadi', Baswaraju Macha' ${ }^{1}$, Prashanthi Mamidi², Sravanthi Manchinella ${ }^{2}$, Achaiah

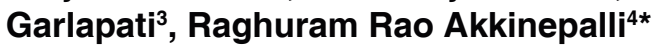

${ }^{1}$ Research Scholar, University College of Pharmaceutical Sciences, Kakatiya University, Warangal, Telangana,INDIA. ${ }^{2}$ Project fellow, University College of Pharmaceutical Sciences, Kakatiya University, Warangal, Telangana, INDIA. ${ }^{3}$ Professor, University College of Pharmaceutical Sciences, Kakatiya University, Warangal, Telangana, INDIA. ${ }^{4}$ (Present Address) Director, National Institute of Pharmaceutical Education and Research (NIPER), SAS Nagar, Punjab, INDIA.

\begin{abstract}
Background: Flavonoids encompasses flavones, isoflavones, flavanones and flavanols each possessing the benzopyranone ring system as the common structural feature, were identified as potent nonsteroidal aromatase inhibitors (NSAIs). Purpose: Azaflavones which were isosteric structural scaffolds of flavonoids were also proven to be potent NSAls. In order to develop new NSAls as cytotoxic agents for breast cancer, we designed some 6-bromo-2-substituted azaflavanones and azaflavone derivatives. Method: Azaflavones and Azaflavonones were synthesized by a reaction of 2-amino-6-bromoacetophenone and various aromatic aldehydes to result in different chalcones (4) using Claisen-Schmidt condensation. Further cyclization of chalcones (4), led to tetrahydroquinoline-4-ones (5) using orthophosphoric acid. In the final oxidative step, the desired dihydroquinoline-4ones (6) were obtained. Results: All the synthesized compounds were characterized by using IR, ${ }^{1} \mathrm{H}$ NMR and ESI-MS data and were evaluated for cytotoxic activity by using MTT assay on MCF-7 cell lines. Conclusion: Compounds with furoyl and pyridyl groups as substituents were found to be potent.
\end{abstract}

Key words: Azaflavones, Azaflavanones, Claisen-Schmidt condensation, Cytotoxicity, MTT assay, FT-IR, NMR.

\section{INTRODUCTION}

Worldwide, breast cancer is considered as the leading cause of death among women (accounting for $35 \%$ of all cancers and $20 \%$ of all cancer deaths). ${ }^{1-3}$ In most of the cases breast cancer proved to be hormonedependent. The tumor progression is dependent on high levels of circulating estrogens, which play a critical role in cancer cell proliferation. Estrogen enhances the growth and proliferation of certain target cells, such as breast epithelial cells and estrogendependent mammary carcinoma cells. It also includes the formation and secretion of various growth factors in established human mammary carcinoma cell lines ${ }^{4-6}$ such as MCF-7, T4TD and ZR-75-1.

Flavonoids are the plant products present in natural food sources, including fruits, vegetables, legumes, whole grains etc. The classes of flavonoids include flavones, isoflavones, flavanones and flavanols, which posseses the benzopyranone ring system as the common structural moiety. The flavonoids present in soy and in rye flour play a protective role in the incidence of breast cancer, as they show inhibitory activities of the aromatase enzyme, ${ }^{7,8}$ thus lowering estrogen biosynthesis and circulating estrogen levels. ${ }^{9,10}$
Submission Date: 01-06-2018; Revision Date: 14-08-2018; Accepted Date: 23-10-2018

DOI: 10.5530/ijper.53.1.16 Correspondence: Prof. Raghuram Rao Akkinepalli,

Director, National Institute of Pharmaceutical Education and Research (NIPER), SAS Nagar, Punjab, INDIA. Phone no: 8790432456 E-mail: rrakkinepally@niper. ac.in

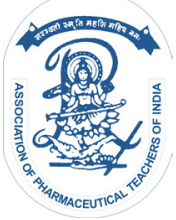

www.ijper.org 


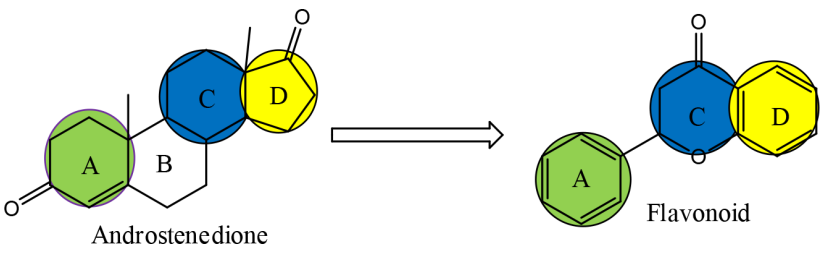

Figure 1: comparison of chemical feature between the model frame work of androstenedione and quinoline-4-one.

Azaflavones, being isosteric structural scaffold of flavonoids, were proven to be potent non-steroidal aromatase inhibitors (NSAIs). Halogenated azaflavones have also been reported to be potent aromatase inhibitors.

Previously, efforts were made to develop novel quinoline derivatives as potent NSAIs ${ }^{11-14}$ from these laboratories. Specifically by chemical modifications on the structural scaffold of quinoline. The binding orientation was predicted in which the $\mathrm{A}, \mathrm{C}$ and $\mathrm{D}$ rings of the quinolines mimic the $\mathrm{A}, \mathrm{C}$ and $\mathrm{D}$ rings of the steroid substrate, respectively (Figure 1). The keto group at $4^{\text {th }}$ position of quinoline undergoes keto-enol tautomerisation.

In continuation of our ongoing research to identify the potent molecules having flavonoid scaffold as AIs, an attempt was made to synthesize azaflavanones (tetrahydroquinoin-4-ones) azaflavones (dihydroquinoin4-ones). For designing these derivatives, we relied on flavonoid skeleton as a structural scaffold for the synthesis of azaflavanones and azaflavones involving bioisosteric modification on ring oxygen with nitrogen. Results are discussed in the present communication.

\section{MATERIALS AND METHODS}

All chemicals and solvents were obtained from Sigma Aldrich or Merck, Mumbai and were used without further purification. Melting points were determined using open capillaries on electrothermal melting point apparatus and are uncorrected. Infrared spectra were recorded on Bruker FTIR spectrophotometer using potassium bromide $(\mathrm{KBr})$ pellet method. Column Chromatography was performed with silica gel $\mathrm{G}_{60} \cdot{ }^{1} \mathrm{H}$ NMR spectra were recorded on Bruker AC $400 \mathrm{MHz}$ spectroscopy using $\mathrm{DMSO} / \mathrm{CDCl}_{3}$ as solvent and TMS as internal standard (chemicals shifts in .ppm). Triple quadrapole mass spectrometer (LCMS) with an Electrospray ionization (ESI) interface was used to obtain the mass spectra. Progress of the reactions was monitored using Thin Layer Chromatography (TLC) sheets with UV Fluorescence (silica gel Merck 60F 254). Ethylacetate and chloroform were used as solvent system (6:4) and spots were visualized using UV lamp.

\section{Synthesis of 2-acetamido-5- bromoacetophenone $(2)^{15}$}

Bromine $(0.8 \mathrm{~g}, 5.6 \mathrm{mM})$ in glacial acetic acid $(10 \mathrm{~mL})$ was added dropwise to a solution of 2-acetamidoacetophenone (1) $(1 \mathrm{~g}, 5.6 \mathrm{mM})$ in glacial acetic acid with stirring at $5-10^{\circ} \mathrm{C}$ for $45 \mathrm{~min}$. Reaction mixture was kept aside for 30 min at RT with occasional shaking and then poured in to $50 \mathrm{~mL}$ of cold water and the solid obtained was filtered and then recrystallized from methanol, to efford compound ' 2 '.

\section{Synthesis of 2-amino-5-bromoacetophenone $(3)^{16}$}

2-Acetamido-5-bromoacetopheone (2, $0.8 \mathrm{~g}, 3.1 \mathrm{mM}$ ) was dissolved in $5 \mathrm{~mL}$ of boiling ethanol and conc. $\mathrm{HCl}$ was added by drop wise and heated and refluxed for 20-30 min. After completion of reaction (monitored by TLC), reaction mixture was poured into ice-cold water, $5 \% \mathrm{NaOH}$ solution was added to make the mixture alkaline. The separated solid was collected and recrystallized from ethanol.

\section{General Procedure for the Synthesis of Chalcones (4a-n): Claisen-Schmidt Condensation}

A solution of sodium hydroxide $(0.255 \mathrm{~g})$ in $3 \mathrm{~mL}$ of water and $4 \mathrm{~mL}$ of absolute ethanol was placed in a $100 \mathrm{~mL}$ conical flask. The flask was immersed in an ice chest at $0^{\circ} \mathrm{C}$. 2-Amino-5-bromoacetophenone (3, $0.64 \mathrm{~g}$, $3 \mathrm{mmol})$ was added to the solution and stirred for one hour. ${ }^{17}$ Different substituted aryl-aldehydes $(3 \mathrm{mmol})$ in ethanol were added to above solution and stirred for 24-36 $\mathrm{h}$ until the reaction was completed (monitored by TLC). The resulting precipitate was separated by filtration, washed with cold water and dried. The crude products were purified by recrystallization from absolute ethanol.

\section{General Procedure for the Synthesis of 6-bromo- 2-Substituted Aryl Tetrahydroquinolin-4-ones (5a- n)}

To a solution of chalcones (4a-n, $3 \mathrm{mM}$ ) in glacial acetic acid $(12 \mathrm{ml})$, orthophosphoric acid $(12 \mathrm{ml})$ was added slowly and refluxed the mixture for $20 \mathrm{~min}$. The reaction mixture was poured into cold water $(100 \mathrm{ml})$ after cooling; the resulting precipitate was filtered and purified by recrystallization to get the corresponding tetrahydroquinoli-4-ones (5a-n).

For instance 6-bromo-2-(4-cyanophenyl)-2,3-dihydroquinolin-4(1H)-one (5a) was synthesized from $4 a$ $(\mathrm{R}=4$-cyanophenyl) characterized based on spectral data. Yield: $80 \%$, yellowish solid, mp: $292-294^{\circ} \mathrm{C}$. 
General Procedure for Synthesis of 6-bromo-2Substitutedaryldihydroquinolin-4-ones (6a-n)

To a mixture tetrahydroquinolin-4-ones (5a-n, $2 \mathrm{mM}$ ) and $0.1 \mathrm{~N} \mathrm{KOH}$ in $\mathrm{CH}_{3} \mathrm{OH}(60 \mathrm{~mL}, 6 \mathrm{mM})$ (di-acetoxyiodo)benzene $(0.709 \mathrm{~g}, 2.2 \mathrm{mM})$ was added at room temperature, the mixture was heated under reflux at $60^{\circ} \mathrm{C}$ for $16 \mathrm{~h}$. After completion of reaction (monitored by TLC), $\mathrm{CH}_{3} \mathrm{OH}$ was evaporated completely, $0.05 \mathrm{~N}$ $\mathrm{HCl}(50 \mathrm{~mL})$ was slowly added to reaction mixture at $0{ }^{\circ} \mathrm{C} \cdot{ }^{18}$ Resulting precipitate was separated by filtration, washed with cold water, and resultant product (6a-n) were recrystallized with methanol and purified by column chromatography.

For instant the 6-bromo-2-(4-cyano phenyl)quinolin-4-ol (6a) was synthesized from 6-bromo-2-(4-cyano phenyl) dihydroquinolin-4- $(1 \mathrm{H})$-one $(5 \mathrm{a})$ by adopting the above general procedure. Yield: 68\%, yellow solid, $\mathrm{mp}: 312-314^{\circ} \mathrm{C}$.

\section{Cytotoxicity on MCF-7 Cell Lines ${ }^{19,20}$}

Cell viability was evaluated by the MTT Assay with three independent experiments with six concentrations of compounds in triplicates. MCF-7 cell lines were trypsinized and performed the tryphan blue assay to know viable cells in cell suspension. Cells were counted by haemocytometer and seeded at density of $5.0 \times$ $10^{3}$ cells / well in $100 \mu \mathrm{l}$ media in 96 well plate culture medium and incubated overnight at $37^{\circ} \mathrm{C}$. After incubation, the old media was taken off and fresh media $(100 \mu \mathrm{l})$ with different concentrations of test compound was
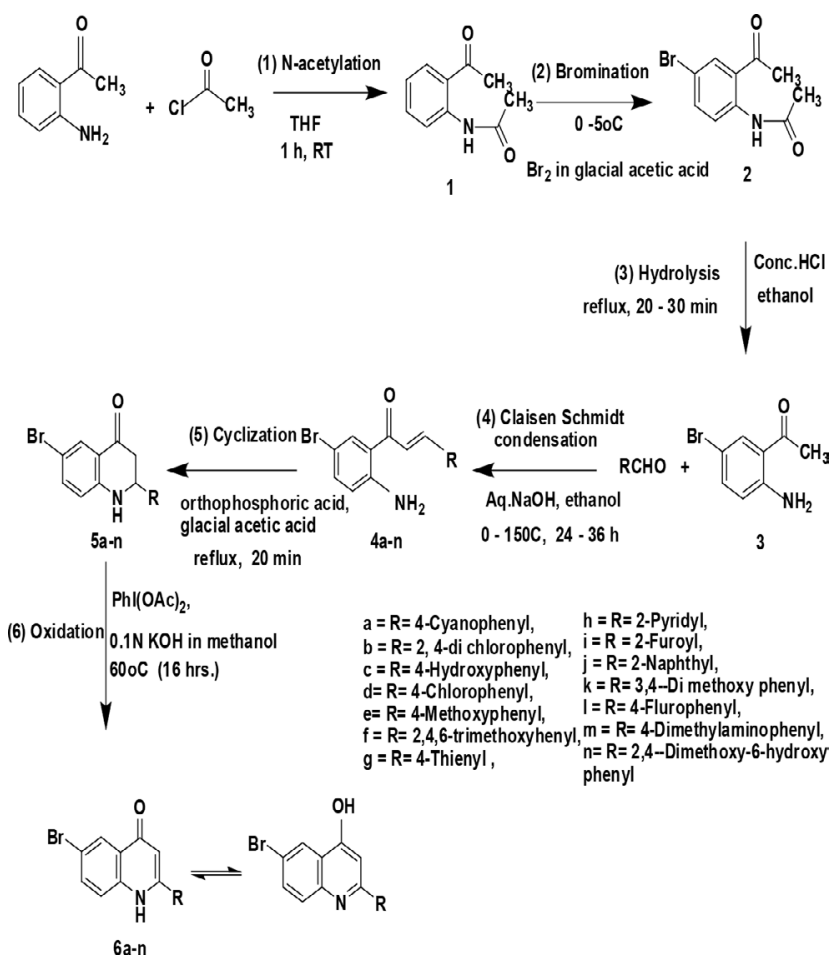

Figure 2: Scheme. added in representative wells in 96 plate. After 48 hrs., the drug solution was discarded and fresh media with MT'T solution $\left(0.5 \mathrm{mg} / \mathrm{mL}^{-1)}\right.$ was added to each well and plates were incubated at $37^{\circ} \mathrm{C}$ for $3 \mathrm{~h}$. At the end of incubation time, precipitates are formed as a result of the reduction of the MT'T salt to chromophore formazan crystals by the cells with metabolically active mitochondria. The optical density of solubilised crystals in DMSO was measured at $570 \mathrm{~nm}$ on a microplate reader. The percentage growth inhibition was calculated using the following formula and concentration of test drug needed to inhibit cell growth by $50 \%$ values is generated from the dose-response curves for each cell line using with origin software.

$$
\% \text { inhibition }=\frac{100\{\text { Control }- \text { Treatment }\}}{\text { Control }}
$$

\section{RESULTS AND DISCUSSION}

\section{Chemistry}

2-Amino acetophenone by reacting with acetyl chloride in the presence of THF for 1 hour at room temperature yields 2-acetamido acetophenone (1). Bromine in glacial acetic acid was added drop wise at $5-10^{\circ} \mathrm{C}$ for 45 mins at RT to give 2-acetamido 5-bromo acetophenone (2). The compound (2) upon hydrolysis in the presence of Conc. $\mathrm{HCl}$ and hot ethanol (98\%) gives 2-amino-5-bromoacetophenone (3). This compound (3) was treated with different substituted aryl aldehydes in the presence of ethanol and aqueous $\mathrm{NaOH}$ at $0-15^{\circ} \mathrm{C}$ for $24 \mathrm{~h}$ (Claisen Schmidt condensation) to get the corresponding chalcones $(\mathbf{4} \mathbf{a}-\mathbf{n})$.

These chalcones (4a-n) were cyclised using orthophosphoric acid to give the final product 6-bromo-2-substituted aryl tetrahydro quinoline-4-ones (azaflavanones) (5a-n). The compounds (5a-n) upon oxidation and by the treatment with $0.1 \mathrm{~N} \mathrm{KOH}$ in methanol and diacetoxy iodo benzene gave the corresponding 6-bromo-2-substituted aryl dihydro quinoline-4-ones (6a-n) (azaflavones).

The final compounds, were purified by recrystallization with methanol or ethanol or by column chromatography. The compounds (5a-n and $\mathbf{6}$ a-n) were confirmed on the basis of their physical and spectral data. For instance, the IR spectrum of the compound 5a showed $\mathrm{NH}$ absorption band at $3343 \mathrm{~cm}^{-1}$, aromatic C-H stretch at $3035 \mathrm{~cm}^{-1}$, an absorption band observed at $2225 \mathrm{~cm}^{-1}$ due to $\mathrm{CN}$ and carbonyl stretch band was observed at $1674, \mathrm{~cm}^{-1} .{ }^{1} \mathrm{H}$ NMR $\left(\mathrm{CDCl}_{3}-\mathrm{d} 1\right)$ showed a singlet at 7.92 assignable to $\mathrm{H}-5$ of quinoline. Two doublets at $7.56(\mathrm{~J}=4.8 \mathrm{~Hz})$ and $7.47(\mathrm{~J}=6.8 \mathrm{~Hz})$ each for two protons are assignable to H-3', H-5' and H-2', H-6' respectively. 
Two doublets at $7.36(J=5.2 \mathrm{~Hz})$ and $6.53(J=4.8 \mathrm{~Hz})$ each for one proton are due to $\mathrm{H}-7$ and $\mathrm{H}-8$ of quinolone. A triplet at $4.52(\mathrm{~J}=7.2 \mathrm{~Hz})$ for one proton is due to $\mathrm{H}-2$ and a doublet at $\mathrm{H}-3$ of quinoline nucleus. A broad singlet at 4.62 for one proton is assigned to $\mathrm{NH}$. Mass spectrum showed $\mathrm{M}+$ and $\mathrm{M}++1$ peaks at $\mathrm{m} / \mathrm{z} 327$ and 328, and thus confirms the formation of 6-bromo2-(4-cyanophenyl)-2,3-tetrahydroquinoli-4(1H)-one.

The IR spectrum of the azaflavones $\mathbf{6}(\mathbf{a}-\mathbf{n})$ showed characteristic stretching absorption bands at 1674-1690 $\mathrm{cm}^{-1}$ due to the carbonyl group, at $3343-3361 \mathrm{~cm}^{-1}$ due to the presence $\mathrm{NH}$ stretching, at $1580-1593 \mathrm{~cm}^{-1}$ due to $\mathrm{C}=\mathrm{C}$ and at $3063-3093 \mathrm{~cm}^{-1}$ due to aromatic hydrogens. The ${ }^{1} \mathrm{H}$ NMR spectra of the compounds $6(\mathrm{a}-\mathrm{n})$ in $\mathrm{CDCl}_{3}$ showed the presence of a single broad peak at $4.6 \mathrm{ppm}$, integrated to 1 proton, which was assigned to $\mathrm{NH}$ proton. In addition to the expected aromatic protons, a sharp singlet for one proton appeared at $\delta 6.9 \mathrm{ppm}$ assignable to $=\mathrm{C}-\mathrm{H}$ proton of quinoline ring. All the synthesized compounds showed their molecular ion peaks as base peak in ESI-MS spectra.

\section{Spectral Characterisation of Compounds 5a-n}

\section{6-Bromo-2-(4'-cyanophenyl)-1,2,3,4-tetrahydro} quinolin-4-one (5a))

Yield: $80 \%$, yellowish solid, mp: $292-293^{\circ} \mathrm{C}$; FT-IR (KBr, $\left.\mathrm{cm}^{-1}, \mathrm{v}\right): 3343 \mathrm{~cm}^{-1}(\mathrm{NH}), 3035 \mathrm{~cm}^{-1}(\mathrm{C}=\mathrm{H}), 2926 \mathrm{~cm}^{-1}(\mathrm{C}-\mathrm{H})$, $2225 \mathrm{~cm}^{-1}(\mathrm{CN}), 1674 \mathrm{~cm}^{-1}(\mathrm{C}=\mathrm{O}), 1562 \mathrm{~cm}^{-1}(\mathrm{C}=\mathrm{C})$; ${ }^{1} \mathrm{H}$ NMR: $\left(\mathrm{CDCl}_{3}-\mathrm{d}_{1}\right): 7.92(1 \mathrm{H}, \mathrm{s}, \mathrm{H}-5), 7.56(1 \mathrm{H}, \mathrm{d}$, $J=4.8 \mathrm{~Hz}, \mathrm{H}-3^{\prime}, \mathrm{H}-5$ '), 7.47 (2H, d, $J=6.8 \mathrm{~Hz}, \mathrm{H}-2$ ', H-6'), $7.36(1 \mathrm{H}, \mathrm{d}, J=2.4 \mathrm{~Hz}, \mathrm{H}-7), 6.53(1 \mathrm{H}, J=4.8$ $\mathrm{Hz}, \mathrm{H}-8), 4.52(1 \mathrm{H}, \mathrm{t}, J=7.2 \mathrm{~Hz}, \mathrm{H}-2), 4.62(1 \mathrm{H}, \mathrm{bs}$, $\mathrm{NH}), 3.22(2 \mathrm{H}, \mathrm{d}, J=2.4 \mathrm{~Hz}, \mathrm{H}-3$ );ESI-MS [m/z; \%]: $327\left[\mathrm{M}^{+}\right]$329(M++2).

\section{6-Bromo-2-(2, 4-chlorophenyl)-1,2,3,4- tetrahydroquinolin-4-one (5b)}

Yield: $74 \%$, yellowish orange solid, $\mathrm{mp}: 285-287^{\circ} \mathrm{C}$; FT-IR (KBr, cm $\left.{ }^{-1}, \mathrm{v}\right): 3425 \mathrm{~cm}^{-1}(\mathrm{NH}), 3025 \mathrm{~cm}^{-1}(\mathrm{C}=\mathrm{H})$, $2936 \mathrm{~cm}^{-1}(\mathrm{C}-\mathrm{H}), 1751 \mathrm{~cm}^{-1}(\mathrm{C}=\mathrm{O}), 1565 \mathrm{~cm}^{-1}(\mathrm{C}=\mathrm{C})$, $761 \mathrm{~cm}^{-1}(\mathrm{C}-\mathrm{Cl})$; ${ }^{1} \mathrm{H}$ NMR: $\left(\mathrm{CDCl}_{3}-\mathrm{d}_{1}\right): 7.95(1 \mathrm{H}, \mathrm{s}, \mathrm{H}-5)$, 7.75 (1H, s, H-3'), 7.41 (1H, d, J = 6.8 Hz, H-5'), 7.35 $(1 \mathrm{H}, \mathrm{d}, J=2.4 \mathrm{~Hz}, \mathrm{H}-7), 7.08(1 \mathrm{H}, \mathrm{d}, J=5.2 \mathrm{~Hz}, \mathrm{H}-6$ '), $6.55(1 \mathrm{H}, \mathrm{d}, J=4.8 \mathrm{~Hz}, \mathrm{H}-8), 4.5(1 \mathrm{H}, \mathrm{t}, J=2.4 \mathrm{~Hz}$, H-2), 4.6 (1H, bs, NH), 2.93 (2H, d, J = $2.4 \mathrm{~Hz}, \mathrm{H}-3)$; ESI-MS [m/z;\%]: $371\left[\mathrm{M}^{+}\right] 373\left(\mathrm{M}^{+}+2\right) ; 375(\mathrm{M}++4)$.

\section{6-Bromo-2-(4-hydroxyphenyl)-1,2,3,4- tetrahydroquinolin-4-one (5c)}

Yield: $78 \%$, pale yellow solid, mp: $291-293{ }^{\circ} \mathrm{C}$; FT-IR $\left(\mathrm{KBr}, \mathrm{cm}^{-1}, \mathrm{v}\right): 3415 \mathrm{~cm}^{-1}(\mathrm{NH}), 3036 \mathrm{~cm}^{-1}(\mathrm{C}=\mathrm{H}), 2918$ $\mathrm{cm}^{-1}(\mathrm{C}-\mathrm{H}), 1765 \mathrm{~cm}^{-1}(\mathrm{C}=\mathrm{O}), 1551 \mathrm{~cm}^{-1}(\mathrm{C}=\mathrm{C}) ;{ }^{1} \mathrm{H}$ NMR: $\left(\mathrm{CDCl}_{3}-\mathrm{d}_{1}\right): 9.43(1 \mathrm{H}, \mathrm{s}, \mathrm{OH}), 7.94(1 \mathrm{H}, \mathrm{s}, \mathrm{H}-5)$,
$7.32(1 \mathrm{H}, \mathrm{d}, J=2.4 \mathrm{~Hz}, \mathrm{H}-7), 7.15(2 \mathrm{H}, \mathrm{d}, J=6.4 \mathrm{~Hz}$, H-2', H-6'), 6.72 (2H, d, J = 4.2 Hz, H-3', H-5'), 6.55 $(1 \mathrm{H}, J=4.8 \mathrm{~Hz}, \mathrm{H}-8), 4.55(1 \mathrm{H}, \mathrm{t}, J=7.2 \mathrm{~Hz}, \mathrm{H}-2), 4.64$ $(1 \mathrm{H}, \mathrm{bs}, \mathrm{NH}), 3.2(2 \mathrm{H}, \mathrm{d}, J=2.4 \mathrm{~Hz}, \mathrm{H}-3)$; ESI-MS [m/z; \%]: $317\left[\mathrm{M}^{+}\right] ; 319\left(\mathrm{M}^{+}+2\right)$.

\section{6-Bromo-2-(4-chlorophenyl)-1,2,3,4- tetrahydroquinolin-4-one (5d)}

Yield: $82 \%$, Light orange solid, mp: $264-266^{\circ} \mathrm{C}$; FT-IR $\left(\mathrm{KBr}, \mathrm{cm}^{-1}, \mathrm{v}\right): 3493 \mathrm{~cm}^{-1}(\mathrm{NH}), 3062 \mathrm{~cm}^{-1}(\mathrm{C}=\mathrm{H}), 2917 \mathrm{~cm}^{-1}$ $(\mathrm{C}-\mathrm{H}), 1721 \mathrm{~cm}^{-1}(\mathrm{C}=\mathrm{O}), 1580 \mathrm{~cm}^{-1}(\mathrm{C}=\mathrm{C}), 765 \mathrm{~cm}^{-1}$ (C-Cl); ${ }^{1} \mathrm{H}-\mathrm{NMR}:\left(\mathrm{CDCl}_{3}-\mathrm{d}_{1}\right): 8.0(1 \mathrm{H}, \mathrm{s}, \mathrm{H}-5), 7.75$ $\left(2 \mathrm{H}, \mathrm{d}, J=4.8 \mathrm{~Hz}, \mathrm{H}-3^{\prime}, \mathrm{H}-5^{\prime}\right), 7.6(2 \mathrm{H}, \mathrm{d}, J=6.4 \mathrm{~Hz}$, H-2',H-6'), 7.45 (1H, d, J = 5.2 Hz, H-7), $6.65(1 \mathrm{H}, \mathrm{d}$, $J=4.8 \mathrm{~Hz}, \mathrm{H}-8), 4.8(1 \mathrm{H}, \mathrm{t}, \mathrm{H}-2), 4.6(1 \mathrm{H}, \mathrm{bs}, \mathrm{NH}), 2.8$ $(2 \mathrm{H}, \mathrm{d}, J=2.4 \mathrm{~Hz}, \mathrm{H}-3) ; \mathrm{ESI}-\mathrm{MS}$ [m/z; \%]: $336\left[\mathrm{M}^{+}\right]$ $338\left(\mathrm{M}^{+}+2\right) ; 340\left(\mathrm{M}^{+}+4\right)$.

\section{6-Bromo-2-(4-methoxyphenyl)-1,2,3,4- tetrahydroquinolin-4-one (5e)}

Yield: $75 \%$, light yellowish, mp: $295-297{ }^{\circ} \mathrm{C}$; FT-IR $\left(\mathrm{KBr}, \mathrm{cm}^{-1}, \mathrm{v}\right): 3323 \mathrm{~cm}^{-1}(\mathrm{NH}), 3026 \mathrm{~cm}^{-1}(\mathrm{C}=\mathrm{H}), 2928 \mathrm{~cm}^{-1}$ (C-H), $1672 \mathrm{~cm}^{-1}(\mathrm{C}=\mathrm{O}), 1565 \mathrm{~cm}^{-1}(\mathrm{C}=\mathrm{C}), 1334 \mathrm{~cm}^{-1}$ and $1092 \mathrm{~cm}^{-1}(\mathrm{C}-\mathrm{O}-\mathrm{C}) ;{ }^{1} \mathrm{H}$ NMR: $\left(\mathrm{CDCl}_{3}-\mathrm{d}_{1}\right): 7.96$ $(1 \mathrm{H}, \mathrm{s}, \mathrm{H}-5), 7.32(1 \mathrm{H}, \mathrm{d}, J=2.4 \mathrm{~Hz}, \mathrm{H}-7), 6.94(2 \mathrm{H}, \mathrm{d}$, $J=2.4 \mathrm{~Hz}, \mathrm{H}-3$ ', H-5'), 6.53 (1H, J = 4.8 Hz, H-8), 4.52 $(1 \mathrm{H}, \mathrm{t}, J=7.2 \mathrm{~Hz}, \mathrm{H}-2), 4.62(1 \mathrm{H}, \mathrm{bs}, \mathrm{NH}), 3.85$ (3h, s, H-4'), 3.22 (2H, d, $J=2.4 \mathrm{~Hz}, \mathrm{H}-3)$; ESI-MS [m/z; \%]: $332\left[\mathrm{M}^{+}\right]$334( $\left(\mathrm{M}^{+}+2\right)$.

\section{6-Bromo-2-(2,4,6-trimethoxyphenyl)-2,3- dihydroquinolin-4(1H)-one (5f)}

Yield: $75 \%$, light brown, mp: $273-275^{\circ} \mathrm{C}$; FT-IR (KBr, $\left.\mathrm{cm}^{-1}, \mathrm{v}\right): 3328 \mathrm{~cm}^{-1}(\mathrm{NH}), 3021 \mathrm{~cm}^{-1}(\mathrm{C}=\mathrm{H}), 2925 \mathrm{~cm}^{-1}$ $(\mathrm{C}-\mathrm{H}), 1675 \mathrm{~cm}^{-1}(\mathrm{C}=\mathrm{O}), 1568 \mathrm{~cm}^{-1}(\mathrm{C}=\mathrm{C}), 1351 \mathrm{~cm}^{-1}$ and $1082 \mathrm{~cm}^{-1}(\mathrm{C}-\mathrm{O}-\mathrm{C}), ;{ }^{1} \mathrm{H}$ NMR: $\left(\mathrm{CDCl}_{3}-\mathrm{d}_{1}\right): 7.96$ (1H, s, H-5), 7.32 (1H, d, J = 2.4 Hz, H-7), $6.53(1 \mathrm{H}, J$ $=4.8 \mathrm{~Hz}, \mathrm{H}-8), 6.2(2 \mathrm{H}, \mathrm{d}, J=6.2 \mathrm{~Hz}, \mathrm{H}-3$ ', H-5' $) 4.52$ $(1 \mathrm{H}, \mathrm{t}, J=7.2 \mathrm{~Hz}, \mathrm{H}-2), 4.62(1 \mathrm{H}, \mathrm{bs}, \mathrm{NH}), 3.83(9 \mathrm{H}, \mathrm{s}$, H-2', H-4', H-6'), 3.22 (2H, d, J = 2.4 Hz, H-3); ESI-MS [m/z; \%]: $392\left[\mathrm{M}^{+}\right]$394( $\left.\mathrm{M}^{+}+2\right)$.

\section{6-Bromo-2-(thien-2-yl)-1,2,3,4-tetrahydroquinolin- 4-one $(5 \mathrm{~g})$}

Yield: $70 \%$, light yellow, mp: $254-256{ }^{\circ} \mathrm{C}$; FT-IR $\left(\mathrm{KBr}, \mathrm{cm}^{-1}, \mathrm{v}\right): 3322 \mathrm{~cm}^{-1}(\mathrm{NH}), 3018 \mathrm{~cm}^{-1}(\mathrm{C}=\mathrm{H}), 2932 \mathrm{~cm}^{-1}$ (C-H), $1655 \mathrm{~cm}^{-1}$ (C=O), $1555 \mathrm{~cm}^{-1}(\mathrm{C}=\mathrm{C}),{ }^{1} \mathrm{H}$ NMR: $\left(\mathrm{CDCl}_{3}-\mathrm{d}_{1}\right): 7.96(1 \mathrm{H}, \mathrm{s}, \mathrm{H}-5), 7.42(1 \mathrm{H}, \mathrm{d}, J=1.2 \mathrm{~Hz}$, H-5'), $7.32(1 \mathrm{H}, \mathrm{d}, J=2.4 \mathrm{~Hz}, \mathrm{H}-7), 6.93(1 \mathrm{H}, \mathrm{t}, J=8.2$ $\left.\mathrm{Hz}, \mathrm{H}-4^{\prime}\right), 6.85\left(1 \mathrm{H}, \mathrm{d}, J=8.6 \mathrm{~Hz}, \mathrm{H}-3^{\prime}\right) 6.53(1 \mathrm{H}$, $J=4.8 \mathrm{~Hz}, \mathrm{H}-8), 4.52(1 \mathrm{H}, \mathrm{t}, J=7.2 \mathrm{~Hz}, \mathrm{H}-2), 4.62$ $(1 \mathrm{H}, \mathrm{bs}, \mathrm{NH}), 3.22(2 \mathrm{H}, \mathrm{d}, J=2.4 \mathrm{~Hz}, \mathrm{H}-3)$; ESI-MS [m/z;\%]: $309\left[\mathrm{M}^{+}\right]$311( $\left.\mathrm{M}^{+}+2\right)$. 


\section{6-Bromo-2-(pyridin-2-yl)-1,2,3,4- tetrahydroquinolin-4-one (5h)}

Yield: $74 \%$, thick orange solid, mp: $225-228^{\circ} \mathrm{C}$; FT-IR $\left(\mathrm{KBr}, \mathrm{cm}^{-1}, \mathrm{v}\right): 3321 \mathrm{~cm}^{-1}(\mathrm{NH}), 3020 \mathrm{~cm}^{-1}(\mathrm{C}=\mathrm{H}), 2938 \mathrm{~cm}^{-1}$ $(\mathrm{C}-\mathrm{H}), 1626 \mathrm{~cm}^{-1}(\mathrm{C}=\mathrm{O}), 1601 \mathrm{~cm}^{-1}(\mathrm{C}=\mathrm{N}), 1563 \mathrm{~cm}^{-1}$ $(\mathrm{C}=\mathrm{C}) ;{ }^{1} \mathrm{H}$ NMR: $\left(\mathrm{CDCl}_{3}-\mathrm{d}_{1}\right): 8.45(1 \mathrm{H}, \mathrm{d}, J=5.4 \mathrm{~Hz}$, H-6'), 7.96 (1H, s, H-5), 7.75(1H, t, J=6.2 Hz, H- 4' ), $7.46\left(1 \mathrm{H}, \mathrm{d}, J=2.8 \mathrm{~Hz}, \mathrm{H}-3^{\prime}\right), 7.32(1 \mathrm{H}, \mathrm{d}, J=2.4 \mathrm{~Hz}$, H-7), $7.2\left(1 \mathrm{H}, \mathrm{d}, J=4.2 \mathrm{~Hz}, \mathrm{H}-5^{\prime}\right), 6.53(1 \mathrm{H}, J=4.8 \mathrm{~Hz}$, $\mathrm{H}-8), 4.52(1 \mathrm{H}, \mathrm{t}, J=7.2 \mathrm{~Hz}, \mathrm{H}-2), 4.62(1 \mathrm{H}, \mathrm{bs}, \mathrm{NH})$, $3.22(2 \mathrm{H}, \mathrm{d}, J=2.4 \mathrm{~Hz}, \mathrm{H}-3)$; ESI-MS [m/z; \%]: 303 $\left[\mathrm{M}^{+}\right]$305( $\left(\mathrm{M}^{+}+2\right)$.

\section{6-Bromo-2-(Furo-2-yl)-1,2,3,4-tetrahydroquinolin- 4-one (5i)}

Yield: $78 \%$, brown colour solid, mp: $175-178^{\circ} \mathrm{C}$; FT-IR $\left(\mathrm{KBr}, \mathrm{cm}^{-1}, \mathrm{v}\right): 3315 \mathrm{~cm}^{-1}(\mathrm{NH}), 3035 \mathrm{~cm}^{-1}(\mathrm{C}=\mathrm{H}), 2931 \mathrm{~cm}^{-1}$ (C-H), $1631 \mathrm{~cm}^{-1}(\mathrm{C}=\mathrm{O}), 1558 \mathrm{~cm}^{-1}(\mathrm{C}=\mathrm{C}), ;{ }^{1} \mathrm{H}$ NMR: $\left(\mathrm{CDCl}_{3}-\mathrm{d}_{1}\right): 7.96(1 \mathrm{H}, \mathrm{s}, \mathrm{H}-5), 7.65(1 \mathrm{H}, \mathrm{d}, J=5.6 \mathrm{~Hz}$, H-5'), $7.32(1 \mathrm{H}, \mathrm{d}, J=2.4 \mathrm{~Hz}, \mathrm{H}-7), 6.53(1 \mathrm{H}, J=4.8 \mathrm{~Hz}$, H-8), 6.45 (2H, m, H-3', H-4'), $4.52(1 \mathrm{H}, \mathrm{t}, J=7.2 \mathrm{~Hz}$, $\mathrm{H}-2), 4.62(1 \mathrm{H}, \mathrm{bs}, \mathrm{NH}), 3.22(2 \mathrm{H}, \mathrm{d}, J=2.4 \mathrm{~Hz}, \mathrm{H}-3)$; ESI-MS [m/z; \%]: $292\left[\mathrm{M}^{+}\right]$294(M++2), 296( $\left.\mathrm{M}^{+}+4\right)$.

\section{6-Bromo-2-(naphtha-2-yl)-1,2,3,4- tetrahydroquinolin-4-one (5j)}

Yield: $82 \%$, creamish colour solid, mp: $286-288^{\circ} \mathrm{C}$; FT-IR $\left(\mathrm{KBr}, \mathrm{cm}^{-1}, \mathrm{v}\right): 3322 \mathrm{~cm}^{-1}(\mathrm{NH}), 3025 \mathrm{~cm}^{-1}(\mathrm{C}=\mathrm{H})$, $2927 \mathrm{~cm}^{-1}(\mathrm{C}-\mathrm{H}), 1628 \mathrm{~cm}^{-1}(\mathrm{C}=\mathrm{O}), 1543 \mathrm{~cm}^{-1}(\mathrm{C}=\mathrm{C})$; ${ }^{1} \mathrm{H}$ NMR: $\left(\mathrm{CDCl}_{3}-\mathrm{d}_{1}\right): 7.96(1 \mathrm{H}, \mathrm{s}, \mathrm{H}-5), 7.86(3 \mathrm{H}, \mathrm{d}$, $\left.J=7.2 \mathrm{~Hz}, \mathrm{H}-7^{\prime}\right), 7.56\left(2 \mathrm{H}, \mathrm{d}, J=5.2 \mathrm{~Hz}, \mathrm{H}-4^{\prime}, \mathrm{H}-5^{\prime}\right)$, $7.46\left(1 \mathrm{H}, \mathrm{s}, \mathrm{H}-2{ }^{\prime}\right), 7.32(1 \mathrm{H}, \mathrm{d}, J=2.4 \mathrm{~Hz}, \mathrm{H}-7), 7.18$ $\left(1 \mathrm{H}, \mathrm{d}, J=6.2 \mathrm{~Hz}, \mathrm{H}-8^{\prime}\right), 6.53(1 \mathrm{H}, J=4.8 \mathrm{~Hz}, \mathrm{H}-8)$, $4.52(1 \mathrm{H}, \mathrm{t}, J=7.2 \mathrm{~Hz}, \mathrm{H}-2), 4.62(1 \mathrm{H}, \mathrm{bs}, \mathrm{NH}), 3.22$ $(2 \mathrm{H}, \mathrm{d}, J=2.4 \mathrm{~Hz}, \mathrm{H}-3)$; ESI-MS [m/z; \%]: $352\left[\mathrm{M}^{+}\right]$ 354 $\left(\mathrm{M}^{+}+2\right)$.

\section{6-Bromo-2-(3,4-dimethoxyphenyl)-1,2,3,4- tetrahydroquinolin-4-one (5k)}

Yield: $71 \%$, yellowish solid, mp: $172-174{ }^{\circ} \mathrm{C}$; FT-IR $\left(\mathrm{KBr}, \mathrm{cm}^{-1}, \mathrm{v}\right): 3348 \mathrm{~cm}^{-1}(\mathrm{NH}), 3032 \mathrm{~cm}^{-1}(\mathrm{C}=\mathrm{H}), 2927 \mathrm{~cm}^{-1}$ $(\mathrm{C}-\mathrm{H}), 1652 \mathrm{~cm}^{-1}(\mathrm{C}=\mathrm{O}), 1547 \mathrm{~cm}^{-1}(\mathrm{C}=\mathrm{C}), 1332 \mathrm{~cm}^{-1}$ and $1082 \mathrm{~cm}^{-1}$ (C-O-C); ${ }^{1} \mathrm{H}$ NMR: $\left(\mathrm{CDCl}_{3}-\mathrm{d}_{1}\right): 7.96(1 \mathrm{H}, \mathrm{s}$, H-5), 7.32 (1H, d, $J=2.4 \mathrm{~Hz}, \mathrm{H}-7), 6.91\left(1 \mathrm{H}, \mathrm{s}, \mathrm{H}-2^{\prime}\right)$, $6.84(1 \mathrm{H}, \mathrm{d}, J=4.8 \mathrm{~Hz}, \mathrm{H}-5), 6.74(1 \mathrm{H}, \mathrm{d}, J=1.6 \mathrm{~Hz}$, H-6'), $6.53(1 \mathrm{H}, J=4.8 \mathrm{~Hz}, \mathrm{H}-8), 4.52(1 \mathrm{H}, \mathrm{t}, J=7.2 \mathrm{~Hz}$, H-2), 4.62 (1H, bs, NH), 3.85 (6H, s, H-3', H-4'), 3.22 $(2 \mathrm{H}, \mathrm{d}, J=2.4 \mathrm{~Hz}, \mathrm{H}-3) ;$ ESI-MS [m/z; \%]: $362\left[\mathrm{M}^{+}\right]$ 364 $\left(\mathrm{M}^{+}+2\right)$.

\section{6-Bromo-2-(4-flourophenyl)-1,2,3,4- tetrahydroquinolin-4-one (5I)}

Yield: $74 \%$, blackish brown solid, mp: $250-252^{\circ} \mathrm{C}$; FT-IR $\left(\mathrm{KBr}, \mathrm{cm}^{-1}, \mathrm{v}\right): 3342 \mathrm{~cm}^{-1}(\mathrm{NH}), 3028 \mathrm{~cm}^{-1}(\mathrm{C}=\mathrm{H}), 2923 \mathrm{~cm}^{-1}$ $(\mathrm{C}-\mathrm{H}), 1646 \mathrm{~cm}^{-1}(\mathrm{C}=\mathrm{O}), 1538 \mathrm{~cm}^{-1}(\mathrm{C}=\mathrm{C}) ;{ }^{1} \mathrm{H}$ NMR: $\left(\mathrm{CDCl}_{3}-\mathrm{d}_{1}\right): 7.96(1 \mathrm{H}, \mathrm{s}, \mathrm{H}-5), 7.32(1 \mathrm{H}, \mathrm{d}, J=2.4 \mathrm{~Hz}$, H-7), 7.27 (2H, d, J = 4.2 Hz, H-2', H-6'), 7.19( 2H, d, $\left.J=6.3 \mathrm{~Hz}, \mathrm{H}-3^{\prime}, \mathrm{H}-5^{\prime}\right), 6.53(1 \mathrm{H}, J=4.8 \mathrm{~Hz}, \mathrm{H}-8)$, $4.52(1 \mathrm{H}, \mathrm{t}, J=7.2 \mathrm{~Hz}, \mathrm{H}-2), 4.62(1 \mathrm{H}, \mathrm{bs}, \mathrm{NH}), 3.22$ $(2 \mathrm{H}, \mathrm{d}, J=2.4 \mathrm{~Hz}, \mathrm{H}-3)$; ESI-MS [m/z; \%]: $319\left[\mathrm{M}^{+}\right]$ $321(\mathrm{M}++2), 323\left(\mathrm{M}^{+}+4\right)$.

\section{6-Bromo-2-(4-dimethyl amino phenyl)-1,2,3,4- tetrahydroquinolin-4-one $(5 \mathrm{~m})$}

Yield: $80 \%$, orange solid, mp: $278-281^{\circ} \mathrm{C}$; FT-IR $\left(\mathrm{KBr}, \mathrm{cm}^{-1}, \mathrm{v}\right): 3353 \mathrm{~cm}^{-1}(\mathrm{NH}), 3021 \mathrm{~cm}^{-1}(\mathrm{C}=\mathrm{H}), 2932 \mathrm{~cm}^{-1}$ (C-H), $1646 \mathrm{~cm}^{-1}(\mathrm{C}=\mathrm{O}), 1535 \mathrm{~cm}^{-1}(\mathrm{C}=\mathrm{C}) ;{ }^{1} \mathrm{H}$ NMR: $\left(\mathrm{CDCl}_{3}-\mathrm{d}_{1}\right): 7.96(1 \mathrm{H}, \mathrm{s}, \mathrm{H}-5), 7.32(1 \mathrm{H}, \mathrm{d}, J=2.4 \mathrm{~Hz}$, H-7), 7.11(2H, d, J=3.6 Hz, H-2',H-6'), 6.71 (2H, d, J= 3.6 Hz, H-3', H-5'), $6.53(1 \mathrm{H}, J=4.8 \mathrm{~Hz}, \mathrm{H}-8), 4.52(1 \mathrm{H}$, $\mathrm{t}, J=7.2 \mathrm{~Hz}, \mathrm{H}-2), 4.62(1 \mathrm{H}, \mathrm{bs}, \mathrm{NH}), 3.22(2 \mathrm{H}, \mathrm{d}, J=$ $2.4 \mathrm{~Hz}, \mathrm{H}-3)$; ESI-MS [m/z; \%]: $345\left[\mathrm{M}^{+}\right]$347( $\left.\mathrm{M}^{+}+2\right)$.

\section{6-Bromo-2-(2,4-dimethoxy-6-hydroxy phenyl)- 1,2,3,4-tetrahydroquinolin-4-one (5n)}

Yield: $68 \%$, light yellow solid, mp: $145-152^{\circ} \mathrm{C}$; FT-IR $\left(\mathrm{KBr}, \mathrm{cm}^{-1}, \mathrm{v}\right): 3345 \mathrm{~cm}^{-1}(\mathrm{NH}), 3032 \mathrm{~cm}^{-1}(\mathrm{C}=\mathrm{H}), 2928 \mathrm{~cm}^{-1}$ $(\mathrm{C}-\mathrm{H}), 1664 \mathrm{~cm}^{-1}(\mathrm{C}=\mathrm{O}), 1528 \mathrm{~cm}^{-1}(\mathrm{C}=\mathrm{C}) ;{ }^{1} \mathrm{H}$ NMR: $\left(\mathrm{CDCl}_{3}-\mathrm{d}_{1}\right)$ : $9.65(1 \mathrm{H}, \mathrm{s}, \mathrm{H}-6$ '), $7.96(1 \mathrm{H}, \mathrm{s}, \mathrm{H}-5), 7.32$ $(1 \mathrm{H}, \mathrm{d}, J=2.4 \mathrm{~Hz}, \mathrm{H}-7), 6.53(1 \mathrm{H}, J=4.8 \mathrm{~Hz}, \mathrm{H}-8), 6.23$ (2H, s, H-3', H-5'), 4.52 (1H, t, J = 7.2 Hz, H-2), 4.62 (1H, bs, NH), 3.83 (6H, s, H-2', H-4'), $3.22(2 \mathrm{H}, \mathrm{d}$, $J=2.4 \mathrm{~Hz}, \mathrm{H}-3)$; ESI-MS [m/z; \%]: $378\left[\mathrm{M}^{+}\right]$380(M+2).

Spectral Characterisation of 6-Bromo-

2Substituted-aryldihydroquinolin-4-ones (6a-n) $\div$

\section{6-Bromo-2-(4'-cyanophenyl)-2,3-dihydro}

\section{quinolin-4(1H)-one (6a)(Figure 3-5)}

Yield: $68 \%$, yellow solid, mp: $292-294^{\circ} \mathrm{C}$, FT-IR (KBr, $\left.\mathrm{cm}^{-1}, \mathrm{v}\right): 3443 \mathrm{~cm}^{-1}(\mathrm{NH}), 2225(\mathrm{CN}), 1674 \mathrm{~cm}^{-1}(\mathrm{C}=\mathrm{O})$, $1501 \mathrm{~cm}^{-1}(\mathrm{C}=\mathrm{C})$; ${ }^{1} \mathrm{H}-\mathrm{NMR}:\left(\mathrm{CDCl}_{3}-\mathrm{d}_{1}\right): 7.86(1 \mathrm{H}, \mathrm{s}$, H-5), 7.87 (2H,d, $\left.J=3.6 \mathrm{~Hz}, \mathrm{H}-3^{\prime}, \mathrm{H}^{\prime} 5^{\prime}\right), 7.57(1 \mathrm{H}, \mathrm{d}$, $J=5.8 \mathrm{~Hz}, \mathrm{H}-7), 7.45\left(2 \mathrm{H}, \mathrm{d}, J=2.8 \mathrm{~Hz}, \mathrm{H}-2^{\prime}, \mathrm{H}-6^{\prime}\right)$, $6.54(1 \mathrm{H}, \mathrm{d}, J=4.4 \mathrm{~Hz}, \mathrm{H}-8), 6.43(1 \mathrm{H}, \mathrm{s}, \mathrm{H}-3), 4.51$ (1H, bs, NH); ESI-MS [m/z; \%]: $324\left(\mathrm{M}^{+}, 326(\mathrm{M}++2)\right.$.

\section{6-Bromo-2-(2,4-dichlorophenyl)-2,3- hydroquinolin-4-one(6b)}

Yield: $68 \%$, Pale yellow solid, mp: $319-321^{\circ} \mathrm{C}$, FT-IR $\left(\mathrm{KBr}, \mathrm{cm}^{-1}, \mathrm{v}\right): 3464 \mathrm{~cm}^{-1}(\mathrm{NH}), 1727 \mathrm{~cm}^{-1}(\mathrm{C}=\mathrm{O}), 1590$ $\mathrm{cm}^{-1}(\mathrm{C}=\mathrm{C}) ;{ }^{1} \mathrm{H}-\mathrm{NMR}:\left(\mathrm{CDCl}_{3}-\mathrm{d}_{1}\right): 7.92(1 \mathrm{H}, \mathrm{s}, \mathrm{H}-5)$, $7.52(1 \mathrm{H}, \mathrm{d}, J=7.2 \mathrm{~Hz}, \mathrm{H}-7), 7.48\left(1 \mathrm{H}, \mathrm{s}, \mathrm{H}-3^{\prime}\right), 7.32$ $\left(1 \mathrm{H}, \mathrm{d}, J=5.8 \mathrm{~Hz}, \mathrm{H}-5^{\prime}\right), 7.25\left(1 \mathrm{H}, \mathrm{d}, J=5.4 \mathrm{~Hz}, \mathrm{H}-6^{\prime}\right)$, $6.93(1 \mathrm{H}, \mathrm{s}, \mathrm{H}-3), 6.56(1 \mathrm{H}, \mathrm{d}, J=3.6 \mathrm{~Hz}, \mathrm{H}-8), 4.62$ 
(1H, bs, NH); ESI-MS [m/z; \%]: $369\left(\mathrm{M}^{+}\right), 371\left(\mathrm{M}^{+}+2\right)$; $373(\mathrm{M}++4)$

\section{6-Bromo-2-(4-hydroxyphenyl)-2,3- dihydroquinolin-4(1H)-one(6c)}

Yield: $75 \%$, Pale yellow solid, mp: $325-327^{\circ} \mathrm{C}$, FT-IR $\left(\mathrm{KBr}, \mathrm{cm}^{-1}, \mathrm{v}\right): 3464 \mathrm{~cm}^{-1}(\mathrm{NH}), 1727 \mathrm{~cm}^{-1}(\mathrm{C}=\mathrm{O}), 1590 \mathrm{~cm}^{-1}$ $(\mathrm{C}=\mathrm{C})$; ${ }^{1} \mathrm{H}-\mathrm{NMR}:\left(\mathrm{CDCl}_{3}-\mathrm{d}_{1}\right): 9.45(1 \mathrm{H}, \mathrm{s}, \mathrm{OH}), 7.86$ $(1 \mathrm{H}, \mathrm{s}, \mathrm{H}-5), 7.65(1 \mathrm{H}, \mathrm{d}, J=6.2 \mathrm{~Hz}, \mathrm{H}-7), 7.49(2 \mathrm{H}, \mathrm{d}$, $\left.J=7.2 \mathrm{~Hz}, \mathrm{H}-2^{\prime}, \mathrm{H}-6^{\prime}\right), 7.03(1 \mathrm{H}, \mathrm{d}, J=5.2 \mathrm{~Hz}, \mathrm{H}-8)$, $6.65(2 \mathrm{H}, \mathrm{d}, J=2.4 \mathrm{~Hz}, \mathrm{H}-3$ ', H-5'), 6.55 (1H, s, H-3), 4.62 (1H, bs, NH); ESI-MS [m/z; \%]: $315\left(\mathrm{M}^{+} ; 100 \%\right)$, $317\left(\mathrm{M}^{+}+2\right)$.

\section{6-Bromo-2-(4-chlorophenyl)-2,3-dihydroquinolin- 4(1H)-one(6d)}

Yield: $74 \%$, Pale yellow solid, mp: $321-323{ }^{\circ} \mathrm{C}$, FT-IR $\left(\mathrm{KBr}, \mathrm{cm}^{-1}, \mathrm{v}\right): 3477 \mathrm{~cm}^{-1}(\mathrm{NH}), 1703 \mathrm{~cm}^{-1}(\mathrm{C}=\mathrm{O}), 1593 \mathrm{~cm}^{-1}$ $(\mathrm{C}=\mathrm{C}) ;{ }^{1} \mathrm{H}-\mathrm{NMR}:\left(\mathrm{CDCl}_{3}-\mathrm{d}_{1}\right): 8.0(1 \mathrm{H}, \mathrm{s}, \mathrm{H}-5), 7.75$ $\left(2 \mathrm{H}, \mathrm{d}, J=6.2 \mathrm{~Hz}, \mathrm{H}-3^{\prime}, \mathrm{H}-5^{\prime}\right), 7.6(2 \mathrm{H}, \mathrm{d}, J=2.4 \mathrm{~Hz}$, H-2',H-6'), 7.45 (1H, d, J = 5.8 Hz, H-7), 6.98 (1H, s, H-3), $6.65(1 \mathrm{H}, \mathrm{d}, J=2.2 \mathrm{~Hz}, \mathrm{H}-8), 4.68(1 \mathrm{H}, \mathrm{bs}, \mathrm{NH})$; ESI-MS [m/z; \%]: $334\left[\mathrm{M}^{+} ; 100 \%\right], 336\left[\mathrm{M}^{+}+2 ; 100 \%\right]$; $338(\mathrm{M}++4)$.

\section{6-Bromo-2-(4-methoxyphenyl)-2,3- dihydroquinolin-4-one (6e)(Figure 6,7,8)}

Yield: $65 \%$, light yellow solid, mp: $347-350^{\circ} \mathrm{C}$, FT-IR $\left(\mathrm{KBr}, \mathrm{cm}^{-1}, \mathrm{v}\right): 3326 \mathrm{~cm}^{-1}(\mathrm{NH}), 1682 \mathrm{~cm}^{-1}(\mathrm{C}=\mathrm{O}), 1525$ $\mathrm{cm}^{-1}(\mathrm{C}=\mathrm{C}) 1328 \mathrm{~cm}^{-1}$ and $1082 \mathrm{~cm}^{-1}$ (C-O-C); ${ }^{1} \mathrm{H}-\mathrm{NMR}$ : $\left(\mathrm{CDCl}_{3}-\mathrm{d}_{1}\right): 7.82(1 \mathrm{H}, \mathrm{s}, \mathrm{H}-5), 7.57(1 \mathrm{H}, \mathrm{d}, J=6.2 \mathrm{~Hz}$, H-7), $7.42\left(2 \mathrm{H}, \mathrm{d}, J=2.8 \mathrm{~Hz}, \mathrm{H}-2^{\prime}, \mathrm{H}-6^{\prime}\right), 7.05(2 \mathrm{H}, \mathrm{d}$, $\left.J=4.2 \mathrm{~Hz}, \mathrm{H}-3^{\prime}, \mathrm{H}^{-} 5^{\prime}\right), 6.54(1 \mathrm{H}, \mathrm{d}, J=5.8 \mathrm{~Hz}, \mathrm{H}-8)$, 6.45 (1H, s, H-3), 4.55 (1H, bs, NH), 3.82 (3H,s,H-4'); ESI-MS [m/z; \%]: $329\left(\mathrm{M}^{+}\right), 331\left(\mathrm{M}^{+}+2\right)$.

\section{6-Bromo-2-(2,4,6-trimethoxyphenyl)-2,3- dihydroquinolin-4-one (6f)}

Yield: $73 \%$, brown solid, mp: $312-315^{\circ} \mathrm{C}$, FT-IR $(\mathrm{KBr}$, $\left.\mathrm{cm}^{-1}, \mathrm{v}\right): 3342 \mathrm{~cm}^{-1}(\mathrm{NH}), 1654 \mathrm{~cm}^{-1}(\mathrm{C}=\mathrm{O}), 1532 \mathrm{~cm}^{-1}$ $(\mathrm{C}=\mathrm{C}) 1345 \mathrm{~cm}^{-1}$ and $1095 \mathrm{~cm}^{-1}$ (C-O-C); ${ }^{1} \mathrm{H}-\mathrm{NMR}$ : $\left(\mathrm{CDCl}_{3}-\mathrm{d}_{1}\right): 7.82(1 \mathrm{H}, \mathrm{s}, \mathrm{H}-5), 7.57(1 \mathrm{H}, \mathrm{d}, J=6.2 \mathrm{~Hz}$, $\mathrm{H}-7), 6.52(1 \mathrm{H}, \mathrm{d}, J=5.8 \mathrm{~Hz}, \mathrm{H}-8), 6.45(1 \mathrm{H}, \mathrm{s}, \mathrm{H}-3)$, 6.09 (2H, d, J = 2.4 Hz, H-3', H-5 ) 4.55 (1H, bs, NH), 3.85 (9H,s,H-2', H-4', H-6'); ESI-MS [m/z; \%]: 389 $\left(\mathrm{M}^{+}\right), 391\left(\mathrm{M}^{+}+2\right)$.

\section{6-Bromo-2-(2-thienyl)-2,3-dihydroquinolin-4-one (6g)}

Yield: $75 \%$, yellow solid, mp: $318-320^{\circ} \mathrm{C}$, FT-IR $(\mathrm{KBr}$, $\left.\mathrm{cm}^{-1}, \mathrm{v}\right): 3346 \mathrm{~cm}^{-1}(\mathrm{NH}), 1664 \mathrm{~cm}^{-1}(\mathrm{C}=\mathrm{O}), 1535 \mathrm{~cm}^{-1}$ $(\mathrm{C}=\mathrm{C}) ;{ }^{1} \mathrm{H}-\mathrm{NMR}:\left(\mathrm{CDCl}_{3}-\mathrm{d}_{1}\right): 8.11(1 \mathrm{H}, \mathrm{d}, J=2.4 \mathrm{~Hz}$, H-5'), 8.03 (1H, d, J = 3.6 Hz, H-3'), 7.84 (1H, s, H-5),
$7.57(1 \mathrm{H}, \mathrm{d}, J=6.2 \mathrm{~Hz}, \mathrm{H}-7), 7.43\left(1 \mathrm{H}, \mathrm{t}, J=4.2 \mathrm{~Hz}, \mathrm{H}-4^{\prime}\right)$, $6.52(1 \mathrm{H}, \mathrm{d}, J=5.8 \mathrm{~Hz}, \mathrm{H}-8), 6.45(1 \mathrm{H}, \mathrm{s}, \mathrm{H}-3), 4.55(1 \mathrm{H}$, bs, NH); ESI-MS [m/z; \%]: $305\left(\mathrm{M}^{+}\right), 307(\mathrm{M}++2)$.

\section{6-Bromo-2-(2-pyridyl)-2,3-dihydroquinolin-4-one (6h)}

Yield: $68 \%$, orange solid, mp: $283-285^{\circ} \mathrm{C}$, FT-IR $(\mathrm{KBr}$, $\left.\mathrm{cm}^{-1}, \mathrm{v}\right): 3323 \mathrm{~cm}^{-1}(\mathrm{NH}), 1652 \mathrm{~cm}^{-1}(\mathrm{C}=\mathrm{O}), 1541 \mathrm{~cm}^{-1}$ $(\mathrm{C}=\mathrm{C}), 1523(\mathrm{C}=\mathrm{N}) ;{ }^{1} \mathrm{H}-\mathrm{NMR}:\left(\mathrm{CDCl}_{3}-\mathrm{d}_{1}\right): 8.45(1 \mathrm{H}, \mathrm{d}$, $\left.J=3.8 \mathrm{~Hz}, \mathrm{H}-2^{\prime}, \mathrm{H}-6^{\prime}\right), 7.84$ (1H, s, H-5), 7.57 (1H, d, $J=6.2 \mathrm{~Hz}, \mathrm{H}-7), 7.35$ (3H, m, H-3', H-4' H-5'), 6.52 $(1 \mathrm{H}, \mathrm{d}, J=5.8 \mathrm{~Hz}, \mathrm{H}-8), 6.45$ (1H, s, H-3), 4.55 (1H, bs, $\mathrm{NH})$; ESI-MS [m/z; \%]: $301\left(\mathrm{M}^{+}\right), 303\left(\mathrm{M}^{+}+2\right)$.

\section{6-Bromo-2-(2-furoyl)-2,3-dihydroquinolin-4-one (6i)}

Yield: $71 \%$, light brown solid, mp: $210-213^{\circ} \mathrm{C}$, FT-IR $\left(\mathrm{KBr}, \mathrm{cm}^{-1}, \mathrm{v}\right): 3341 \mathrm{~cm}^{-1}(\mathrm{NH}), 1655 \mathrm{~cm}^{-1}(\mathrm{C}=\mathrm{O}), 1545 \mathrm{~cm}^{-1}$ $(\mathrm{C}=\mathrm{C}), 1523(\mathrm{C}=\mathrm{N}), 1325 \mathrm{~cm}^{-1}$ and $1087 \mathrm{~cm}^{-1} ;{ }^{1} \mathrm{H}-\mathrm{NMR}$ : $\left(\mathrm{CDCl}_{3}-\mathrm{d}_{1}\right): 8.62\left(2 \mathrm{H}, \mathrm{d}, J=3.8 \mathrm{~Hz}, \mathrm{H}-3^{\prime}, \mathrm{H}-5^{\prime}\right), 7.82$ $(1 \mathrm{H}, \mathrm{s}, \mathrm{H}-5), 7.52(1 \mathrm{H}, \mathrm{d}, J=5.2 \mathrm{~Hz}, \mathrm{H}-7), 7.24(1 \mathrm{H}, \mathrm{t}$, $\left.J=4.6 \mathrm{~Hz}, \mathrm{H}-4^{\prime}\right), 6.52(1 \mathrm{H}, \mathrm{d}, J=5.8 \mathrm{~Hz}, \mathrm{H}-8), 6.45$ $(1 \mathrm{H}, \mathrm{s}, \mathrm{H}-3), 4.55(1 \mathrm{H}, \mathrm{bs}, \mathrm{NH})$; ESI-MS [m/z; \%]: 290 $\left(\mathrm{M}^{+}\right), 292(\mathrm{M}++2), 294(\mathrm{M}++4)$.

\section{6-Bromo-2-(2-naphthyl)-2,3-dihydroquinolin-4- one (6j)}

Yield: $73 \%$, light brown solid, mp: $325-327^{\circ} \mathrm{C}$, FT-IR $\left(\mathrm{KBr}, \mathrm{cm}^{-1}, \mathrm{v}\right): 3345 \mathrm{~cm}^{-1}(\mathrm{NH}), 1643 \mathrm{~cm}^{-1}(\mathrm{C}=\mathrm{O}), 1541 \mathrm{~cm}^{-1}$ $(\mathrm{C}=\mathrm{C}) ;{ }^{1} \mathrm{H}-\mathrm{NMR}:\left(\mathrm{CDCl}_{3}-\mathrm{d}_{1}\right): 8.00(2 \mathrm{H}, \mathrm{d}, J=6.8 \mathrm{~Hz}$, H-3', H-6'), 7.91(1H, s, H-5), 7.83 (1H, s, H-2'), 7.75 $\left(1 \mathrm{H}, \mathrm{d}, J=2.4 \mathrm{~Hz}, \mathrm{H}-7^{\prime}\right), 7.57(1 \mathrm{H}, \mathrm{d}, J=6.2 \mathrm{~Hz}, \mathrm{H}-7)$ 7.47 (3H, m, H-4', H-5', H-8'), $6.52(1 \mathrm{H}, \mathrm{d}, J=5.8 \mathrm{~Hz}$, H-8), 6.45 (1H, s, H-3), 4.55 (1H, bs, NH); ESI-MS [m/z; \%]: $350\left(\mathrm{M}^{+}\right), 352\left(\mathrm{M}^{+}+2\right)$.

\section{6-Bromo-2-(3,4-dimethoxyphenyl)-2,3- dihydroquinolin-4-one (6k)}

Yield: $75 \%$, light yellow solid, mp: $255-257^{\circ} \mathrm{C}$, FT-IR $\left(\mathrm{KBr}, \mathrm{cm}^{-1}, \mathrm{v}\right): 3352 \mathrm{~cm}^{-1}(\mathrm{NH}), 1632 \mathrm{~cm}^{-1}(\mathrm{C}=\mathrm{O}), 1536 \mathrm{~cm}^{-1}$ $(\mathrm{C}=\mathrm{C}) ;{ }^{1} \mathrm{H}-\mathrm{NMR}:\left(\mathrm{CDCl}_{3}-\mathrm{d}_{1}\right): 7.85(1 \mathrm{H}, \mathrm{s}, \mathrm{H}-5), 7.52$ $(1 \mathrm{H}, \mathrm{d}, J=6.8 \mathrm{~Hz}, \mathrm{H}-7), 7.24\left(1 \mathrm{H}, \mathrm{t}, J=4.6 \mathrm{~Hz}, \mathrm{H}-2^{\prime}\right)$, $7.05\left(2 \mathrm{H}, \mathrm{d}, J=6.4 \mathrm{~Hz}, \mathrm{H}-5\right.$ ', $\left.\mathrm{H}-6^{\prime}\right) 6.52(1 \mathrm{H}, \mathrm{d}, J=5.8$ $\mathrm{Hz}, \mathrm{H}-8), 6.45$ (1H, s, H-3), 4.55 (1H, bs, NH), 3.83 (6H, s, H-3', H-4'); ESI-MS [m/z; \%]: $360\left(\mathrm{M}^{+}\right), 362$ $\left(\mathrm{M}^{+}+2\right)$.

\section{6-Bromo-2-(4-fluorophenyl)-2,3-dihydroquinolin- 4-one (6I)}

Yield: $78 \%$, light yellow solid, mp: $312-315^{\circ} \mathrm{C}$, FT-IR $\left(\mathrm{KBr}, \mathrm{cm}^{-1}, \mathrm{v}\right): 3347 \mathrm{~cm}^{-1}(\mathrm{NH}), 1625 \mathrm{~cm}^{-1}(\mathrm{C}=\mathrm{O}), 1528 \mathrm{~cm}^{-1}$ $(\mathrm{C}=\mathrm{C}) ;{ }^{1} \mathrm{H}-\mathrm{NMR}:\left(\mathrm{CDCl}_{3}-\mathrm{d}_{1}\right): 7.85(1 \mathrm{H}, \mathrm{s}, \mathrm{H}-5), 7.52$ $(1 \mathrm{H}, \mathrm{d}, J=6.8 \mathrm{~Hz}, \mathrm{H}-7), 7.36(2 \mathrm{H}, \mathrm{d}, J=3.8 \mathrm{~Hz}, \mathrm{H}-2$, 
H-6'), 7.19 (2H, d, J = 4.2 Hz, H-3', H-5'), $6.52(1 \mathrm{H}, \mathrm{d}$, $J=5.8 \mathrm{~Hz}, \mathrm{H}-8), 6.45(1 \mathrm{H}, \mathrm{s}, \mathrm{H}-3), 4.55(1 \mathrm{H}, \mathrm{bs}, \mathrm{NH})$; ESI-MS [m/z;\%]: $318\left(\mathrm{M}^{+}\right), 320\left(\mathrm{M}^{+}+2\right)$.

\section{6-Bromo-2-(4-dimethylaminophenyl)-2,3- dihydroquinolin-4-one $(6 \mathrm{~m})$}

Yield: $65 \%$, orange solid, mp: $318-320^{\circ} \mathrm{C}$, FT-IR $(\mathrm{KBr}$, $\left.\mathrm{cm}^{-1}, \mathrm{v}\right): 3327 \mathrm{~cm}^{-1}(\mathrm{NH}), 1631 \mathrm{~cm}^{-1}(\mathrm{C}=\mathrm{O}), 1532 \mathrm{~cm}^{-1}$ $(\mathrm{C}=\mathrm{C}) ;{ }^{1} \mathrm{H}-\mathrm{NMR}:\left(\mathrm{CDCl}_{3}-\mathrm{d}_{1}\right): 7.85(1 \mathrm{H}, \mathrm{s}, \mathrm{H}-5), 7.75$ $\left(2 \mathrm{H}, \mathrm{d}, J=6.2 \mathrm{~Hz}, \mathrm{H}-2^{\prime}, \mathrm{H}-6^{\prime}\right), 7.52(1 \mathrm{H}, \mathrm{d}, J=6.8 \mathrm{~Hz}$, H-7), $6.71\left(2 \mathrm{H}, \mathrm{d}, J=3.8 \mathrm{~Hz}, \mathrm{H}-3^{\prime}, \mathrm{H}-5^{\prime}\right), 6.52(1 \mathrm{H}, \mathrm{d}$, $J=5.8 \mathrm{~Hz}, \mathrm{H}-8), 6.45$ (1H, s, H-3), 4.55 (1H, bs, NH), $3.06\left(6 \mathrm{H}, \mathrm{s}, \mathrm{N}-\mathrm{CH}_{3}\right)$; ESI-MS [m/z; \%]: $343\left(\mathrm{M}^{+}\right), 345$ $\left(\mathrm{M}^{+}+2\right)$.

\section{6-Bromo-2-(2,4-dimethoxy-6-hydroxyphenyl)-2,3-} dihydroquinolin-4-one (6n)

Yield: $78 \%$, light yellow solid, mp: $220-228^{\circ} \mathrm{C}$, FT-IR $\left(\mathrm{KBr}, \mathrm{cm}^{-1}, \mathrm{v}\right): 3345 \mathrm{~cm}^{-1}(\mathrm{NH}), 1645 \mathrm{~cm}^{-1}(\mathrm{C}=\mathrm{O}), 1542 \mathrm{~cm}^{-1}$ $(\mathrm{C}=\mathrm{C}) ;{ }^{1} \mathrm{H}-\mathrm{NMR}:\left(\mathrm{CDCl}_{3}-\mathrm{d}_{1}\right): 11.85(1 \mathrm{H}, \mathrm{s}, \mathrm{OH}), 7.81$ $(1 \mathrm{H}, \mathrm{s}, \mathrm{H}-5), 7.55(1 \mathrm{H}, \mathrm{d}, J=6.8 \mathrm{~Hz}, \mathrm{H}-7), 6.54(1 \mathrm{H}, \mathrm{d}$, $J=5.8 \mathrm{~Hz}, \mathrm{H}-8), 6.41(1 \mathrm{H}, \mathrm{s}, \mathrm{H}-3), 6.05(2 \mathrm{H}, \mathrm{d}, J=3.6 \mathrm{~Hz}$,

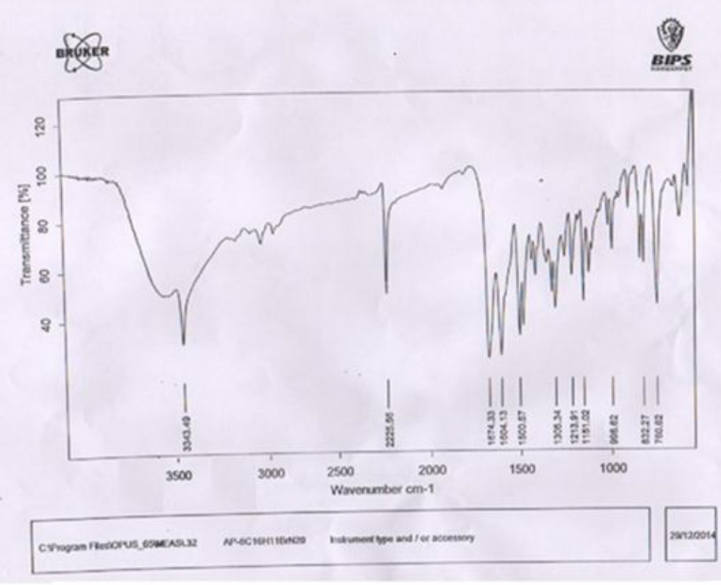

Figure 3: IR spectrum of 6-Bromo-2-(4'-cyano phenyl)-1, 3-dihydroquinoline-4-one (6a).

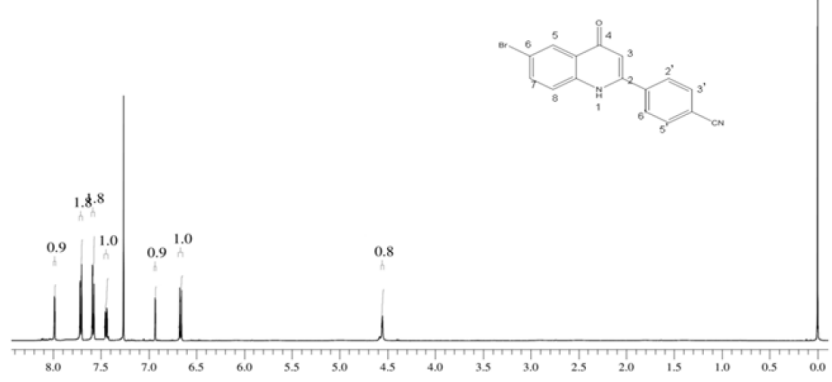

Figure 4: 'H NMR of 6-Bromo-2-(4'-cyano phenyl)-1, 3-dihydroquinoline-4-one (6a).

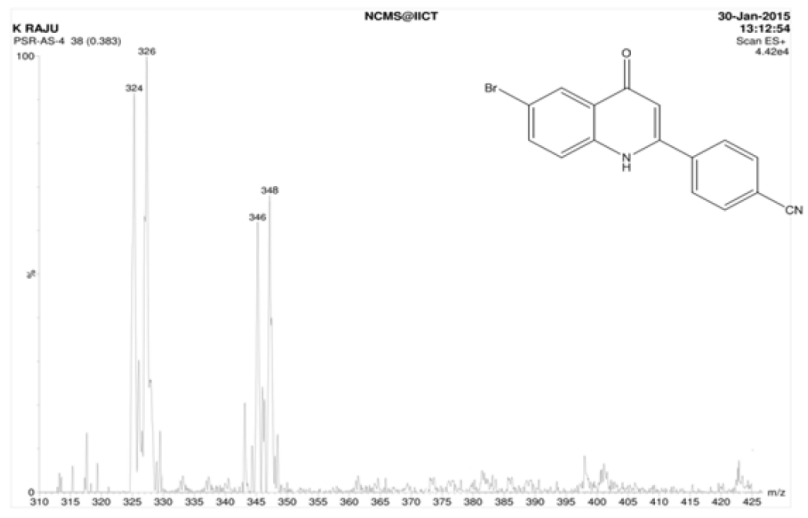

Figure 5: Mass spectrum of 6-Bromo-2-(4'-cyano phenyl)-1, 3-dihydroquinoline-4-one (6a).

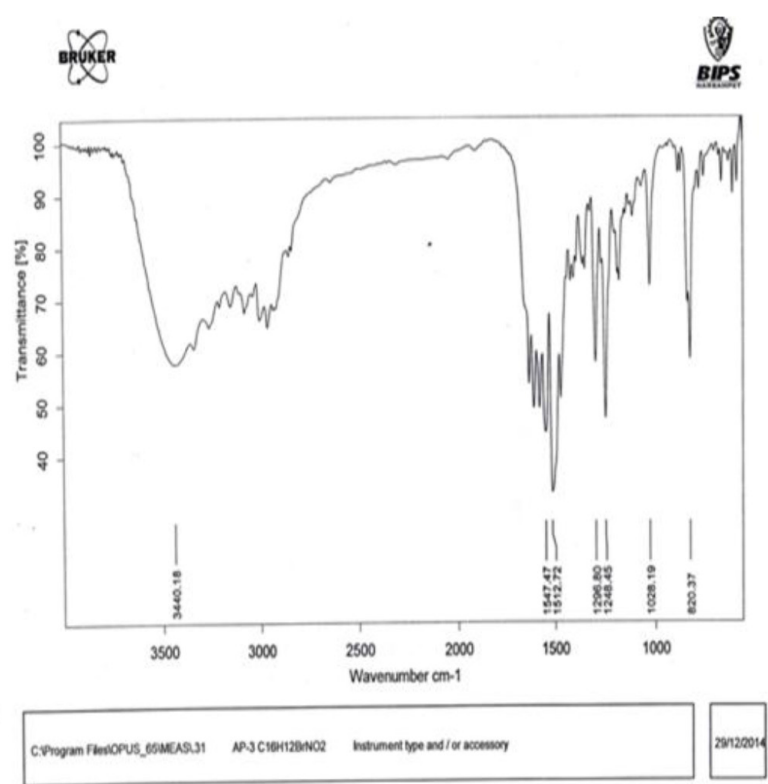

Figure 6: IR spectrum of 6-Bromo-2-(4'-methoxyphenyl)-1, 3-dihydroquinoline-4-one (6e).
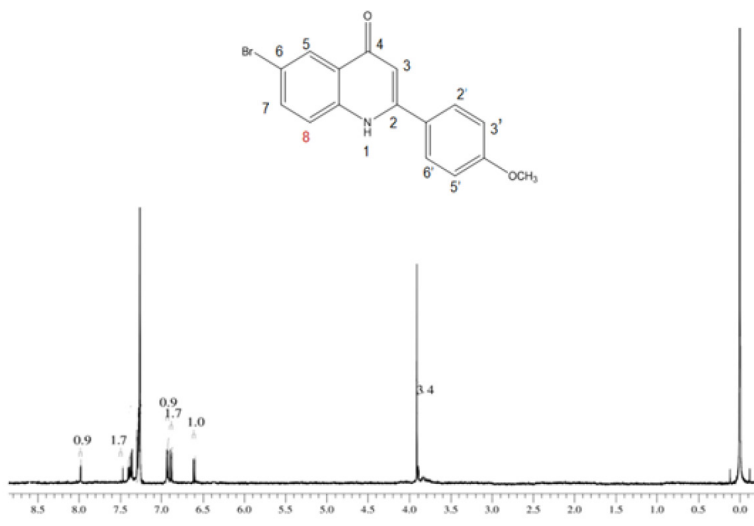

Figure 7: 'H NMR of 6-Bromo-2-(4'-methoxyphenyl)-1, 3-dihydroquinoline-4-one $(6 \mathrm{e})$. 
H-3', H-5'), 4.55 (1H, bs, NH), 3.83 (6H, s, H-2', H-4'); ESI-MS [m/z; \%]: $376\left(\mathrm{M}^{+}\right), 378\left(\mathrm{M}^{+}+1\right)$.

\section{Cytotoxicity on MCF-7 Cell Lines}

Compounds 5a-n (Figure 9) and 6a-n (Figure 10) were screened for in vitro cytotoxic activity (Figure 11) against human breast cancer carcinoma cell lines MCF-7 using MTT assay, where cisplatin was used as a reference. The percentage growth inhibition was calculated and the

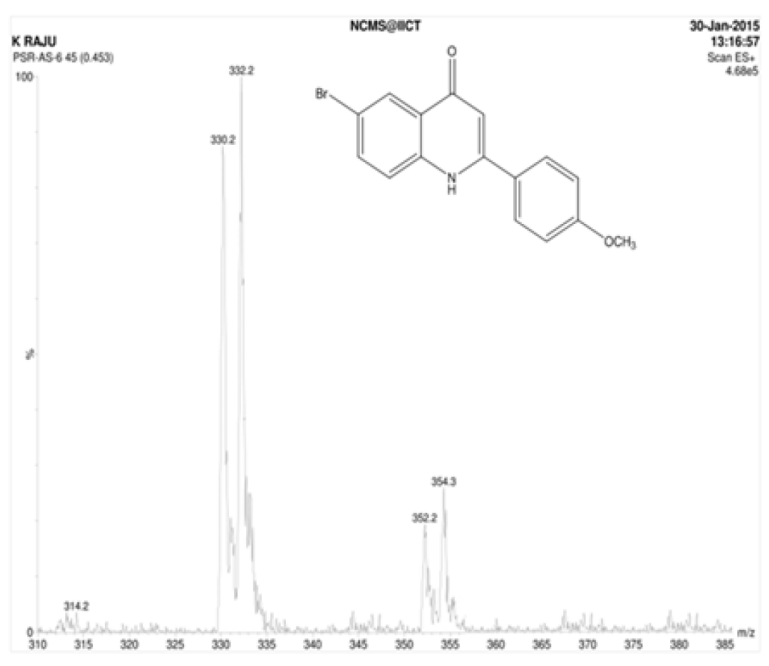

Figure 8: Mass spectrum of 6-Bromo-2-(4'methoxyphenyl)-1,3-dihydroquinoline-4-one(6e).

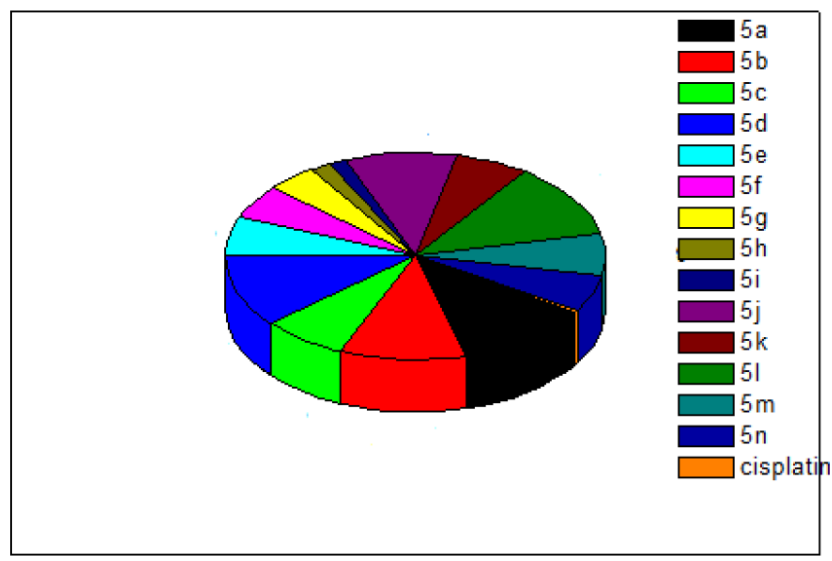

Figure 9: Cytotoxic activity on MCF-7 cell lines for Azaflavanones.

\begin{tabular}{|c|c|c|c|}
\hline Compound & $\mathbf{I C}_{50}(\boldsymbol{\mu} \mathbf{M})$ & Compound & $\mathbf{I C}_{50}(\boldsymbol{\mu M})$ \\
\hline $5 \mathrm{a}$ & $76.61 \pm 1.64$ & $5 \mathrm{~h}$ & $12.67 \pm 1.44$ \\
\hline $5 \mathrm{~b}$ & $74.5 \pm 1.98$ & $5 \mathrm{i}$ & $10.39 \pm 1.24$ \\
\hline $5 \mathrm{c}$ & $50.04 \pm 1.69$ & $5 \mathrm{j}$ & $64.72 \pm 1.41$ \\
\hline $5 \mathrm{~d}$ & $78.63 \pm 173$ & $5 \mathrm{k}$ & $43.13 \pm 1.91$ \\
\hline $5 \mathrm{e}$ & $42.76 \pm 1.41$ & $5 \mathrm{I}$ & $79.42 \pm 1.64$ \\
\hline $5 \mathrm{f}$ & $36.02 \pm 1.91$ & $5 \mathrm{~m}$ & $46.13 \pm 1.83$ \\
\hline $5 \mathrm{~g}$ & $28.27 \pm 1.13$ & $5 \mathrm{n}$ & $38.02 \pm 1.19$ \\
\hline
\end{tabular}

Cisplatin was used as standard (IC $\mathrm{C}_{50}$ value $\left.3.032 \mu \mathrm{M}\right)$.

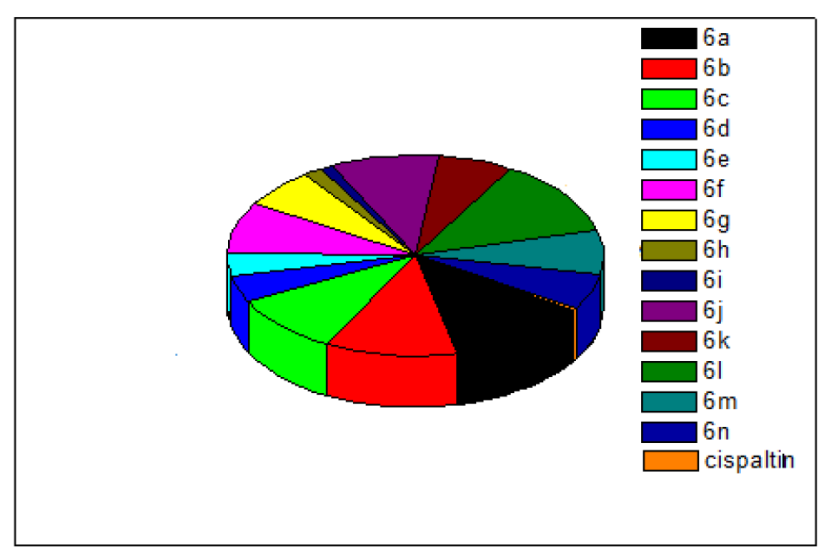

Figure 10: Cytotoxic activity on MCF-7 cell lines for Azaflavones.

\begin{tabular}{|c|c|c|c|}
\hline Compound & $\mathbf{I C}_{50}(\boldsymbol{\mu M})$ & Compound & $\mathbf{I C}_{50}(\boldsymbol{\mu M})$ \\
\hline $6 \mathrm{a}$ & $26.61 \pm 1.44$ & $6 \mathrm{~h}$ & $11.38 \pm 1.83$ \\
\hline $6 \mathrm{~b}$ & $69.35 \pm 1.98$ & $6 \mathrm{i}$ & $9.74 \pm 1.24$ \\
\hline $6 \mathrm{c}$ & $58.41 \pm 1.26$ & $6 \mathrm{j}$ & $56.75 \pm 1.38$ \\
\hline $6 \mathrm{~d}$ & $74.63 \pm 0.95$ & $6 \mathrm{k}$ & $38.64 \pm 1.91$ \\
\hline $6 \mathrm{e}$ & $21.41 \pm 1.41$ & $6 \mathrm{l}$ & $76.53 \pm 1.89$ \\
\hline $6 \mathrm{f}$ & $51.3 \pm 1.91$ & $6 \mathrm{~m}$ & $42.27 \pm 1.35$ \\
\hline $6 \mathrm{~g}$ & $39.7 \pm 1.13$ & $6 \mathrm{n}$ & $35.28 \pm 1.57$ \\
\hline
\end{tabular}

Cisplatin was used as standard (IC $C_{50}$ value $\left.3.032 \mu \mathrm{M}\right)$.
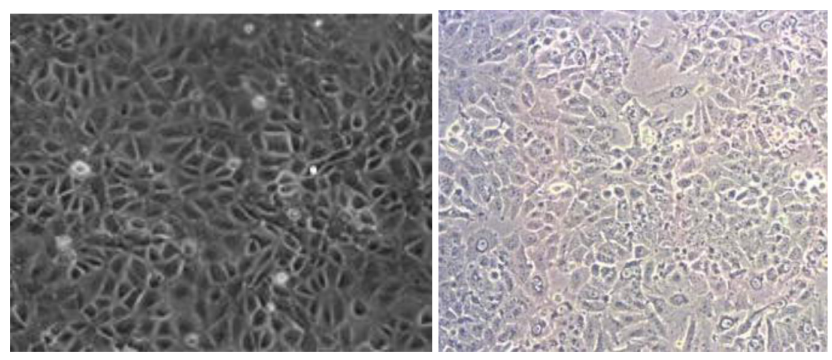

Figure 11: Invitro images of compound $5 \mathrm{~d}$ and $6 \mathrm{e}$.

absorbance was recorded on the ELISA reader at $562 \mathrm{~nm}$ wave length. The absorbance of the test compound was compared with that of DMSO control to get the $\%$ of inhibition. Compounds bearing furoyl and pyridyl groups on azafalvanone moiety exhibited significant cytotoxic activity $\left[\mathrm{IC}_{50}\right.$ at $10.39 \mu \mathrm{g} / \mathrm{mL}$ and $\left.12.67 \mu \mathrm{g} / \mathrm{mL}\right]$. Similarly compounds bearing furoyl and pyridyl groups containing azaflavones also exhibited significant cytotoxic activity $\left[\mathrm{IC}_{50}\right.$ at $9.74 \mu \mathrm{g} / \mathrm{mL}$ and $11.38 \mu \mathrm{g} / \mathrm{mL}$ ] respectively.

\section{CONCLUSION}

In conclusion, the proposed 6-bromo-2-substituted azaflavonones and azaflavone derivatives were synthesized successfully and characterized by physical and spectral data. All the compounds were screened for cytotoxic activity 
on MCF-7 cell lines. Among them the compounds 5i (10.39 \pm 1.24$)$ and $\mathbf{5 h}(12.67$ 1.44) showed good activity. And the compounds $\mathbf{6 i}\left(\mathrm{IC}_{50}=9.74 \mu \mathrm{g} / \mathrm{mL}\right)$ and $\mathbf{6 h}\left(\mathrm{IC}_{50}\right.$ $=11.38 \mu \mathrm{g} / \mathrm{mL}$ ) also exhibited significant activity. With these results it has been found that these are potential leads for developing new drugs for the treatment of cancer.

\section{ACKNOWLEDGMENT}

The authors express their sincere thanks to AICTE for providing funds for this project under QIP to Muthadi Srujana (PHR/214/13). We thank to the National Centre for Cell Science, Pune for providing cell lines for the cytotoxic activity, University College of Pharmaceutical sciences, Kakatiya University, Warangal, Telangana State for facilities and Telangana Academy of Sciences for the support (Core Grant-G/2016-17/25, dt.26-09-2016) and help for obtaining the results of the synthesized compounds.

\section{CONFLICT OF INTEREST}

The authors declare no conflict of interest.

\section{ABBREVIATIONS}

NSAIs: Non steroidal aromatase inhibitors; FTIR: Fourier Transform Infrared; HNMR: Proton Nuclear Magnetic resonance; ESI-MS: Electro Spray Ionization Mass Spectrometry; TLC: Thin Layer Chromatography; TMS: Tetra Methyl Silane; $\mathbf{I C}_{50}$ : Inhibitory Concentration 50; AICTE: All India Council for Technical Education.

\section{REFERENCES}

1. American Cancer Society, Cancer Facts and Figures. 2015

2. Gray JN, Evans B, Taylor L, Rizzo M, Walker. State of the evidence the connection between breast cancer and the environment. Int $\mathrm{J}$ Occup Environ Health. 2009;15(1):43-78.
3. Brueggemeier RW, Richards JA, Joomprabutra S, Bhat AS, Whetstone JL Molecular pharmacology of Aromatase and its regulation by endogenous and exogenous agents. J Steroid Biochem Mol Biol. 2001;79(1-5):75-84.

4. Howell A, Abram P. Clinical development of fulvestrant ('Faslodex'). Cancer Treat Rev. 2005;31:53-9

5. Wang B, Li Q, Shi W, Chen L, Sun J. Design, synthesis and cytotoxic evaluation of novel furo (2,3-b) quinoline derivatives. Chem Biol Drug Des. 2018;91(4):957-61.

6. Ahmed NS, Badahdah KO, Qassar HM. Novel quinoline bearing sulfonamide derivatives and their cytotoxic activity against MCF-7 cell lines. Med Chem Res. 2017;26(6):1201-12.

7. Miller WR. Biological rationale for endocrine therapy in breast cancer. Best Pract Res Clin Endocrinol Metab. 2004;18(1):1-32.

8. ICMR. National Cancer Registry Programme. In consolidated report of the population based cancer registries. 2008: New Delhi.

9. Bhatnagar AS, Hausler A, Schieweck K, Lang M, Bowman R. Highly selective inhibition of estrogen biosynthesis by CGS 20267, a new non-steroidal aromatase inhibitor. J Steroid Biochem Mol Biol. 1990;37(6):1021-7.

10. Adlercreut $\mathrm{H}$, Phytoestrogens. Epidemiology and a possible role in cancer protection Environ. Health Perspect. 1995;103(7):103-12.

11. Rao AR, Murthy J. Novel tetrahydroquinolin-4-ones as aromatase inhibitors. Indian Patent. 2009.

12. Bheemanapalli NL, Kaur A, Arora R, Akkinepally RR, Murthy JN. Synthesis, evaluation of 6,8-dibromo-2-aryl-2,3-dihydroquinolin-4(1H)-ones in MCF-7 (breast cancer) cell lines and their docking studies. Med Chem Res. 2012;21(8):1741-50.

13. Muthadi S, Rao AR. Part of the work was presented in $67^{\text {th }}$ IPC-2015, held at JSS University, Mysore. titled "Synthesis and Evaluation of Some New Quinoline Analogues as Cytotoxic Agents" Abstract No: B-81.

14. Muthadi S, Rao AR. Part of the work was presented in $68^{\text {th }}$ IPC-2016, held at Andhra University, Vishakapatnam. titled "Synthesis of Some Novel Quinoline Derivatives as Aromatase Inhibitors in Breast Cancer Therapy" Abstract No: B-42.

15. Vogel's Text Book of Practical Organic Chemistry. 2010; $5^{\text {th }}$ Edition:918.

16. Vogel's Text Book of Practical Organic Chemistry. 2010; $5^{\text {th }}$ Edition:918-919.

17. Rao AR. Novel tetrahydroquinolines as aromatase inhibitors. U.S patent 20100280070. 2010.

18. Lee JI, Youn JS. A novel synthesis of 2-aryl-4-quinolones from 2-aminobenzoic acids. Bulletin of the Korean Chemical Society. 2008;29(9):1853-6.

19. Nakamura S, Kozuka M, Bastow KF, Tokuda H, Nishino H, Suzuki M, Lee et al. Cancer preventive agents, Part 2: Synthesis and evaluation of 2-phenyl4-quinolone and 9-oxo-9, 10-dihydroacridine derivatives as novel antitumor promoters. Bioorg Med Chem. 2005;13(14):4396-401.

20. Narender ER, Raju S, Harikiran L, Reddy RN, Reddy YN. Multi-component synthesis and in vivo and in vitro anticancer activity of novel arylmethylene bis-isoxazolo [4,5-b]pyridine-N-oxides. Eur J Med Chem. 2012;50:274-9.

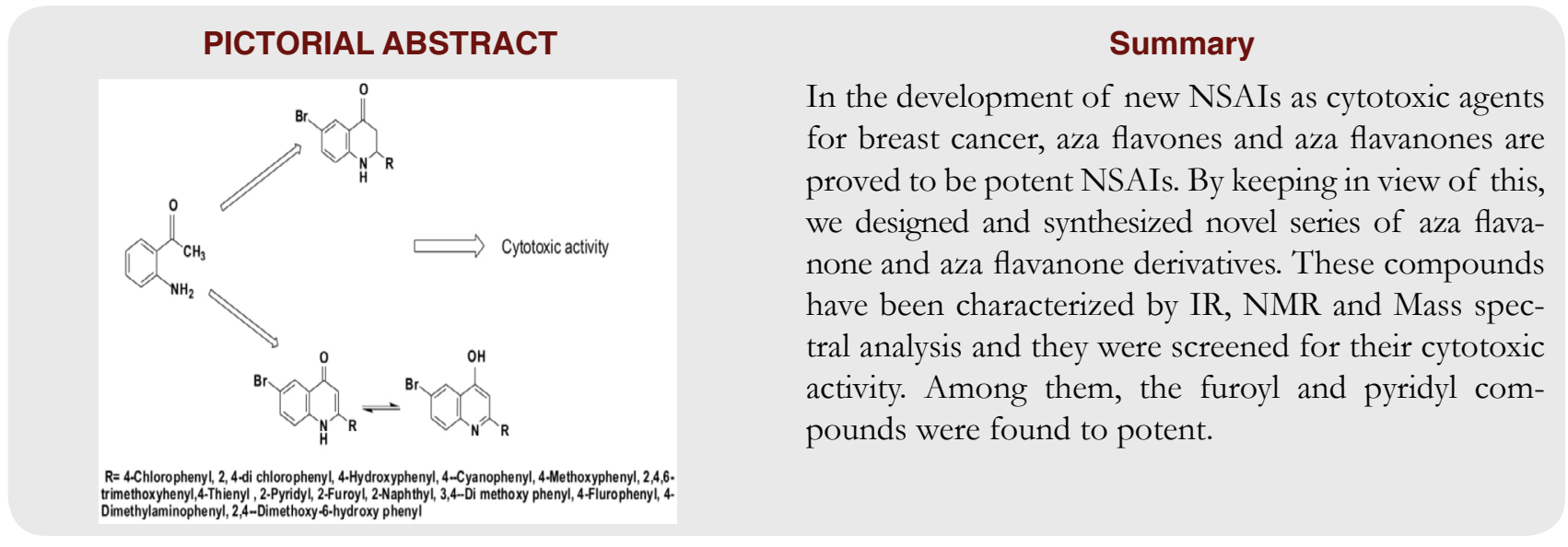




\begin{abstract}
About Authors

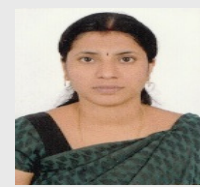

Srujana Muthadi: Research Scholar, University College of Pharmaceutical Sciences, Kakatiya University, Warangal, Telangana, India, Area of interest: Pharmaceutical Chemistry

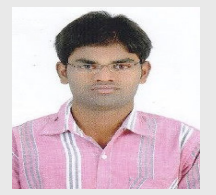

Baswaraju Macha: Research Scholar, University College of Pharmaceutical Sciences, Kakatiya University, Warangal, Telangana, India, Area of interest: Pharmaceutical Chemistry.

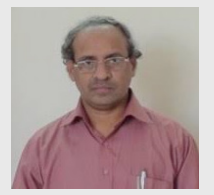

Prof. Dr. Achaiah Garlapati: Professor Department of Pharmaceutical Chemistry, University College of Pharmaceutical Sciences, Kakatiya University, Warangal, Telangana, India. He has 30 years of teaching experience. Area of interest: Design, synthesis and evaluation of New heterocyclic entities as potent Pharmacological agents.

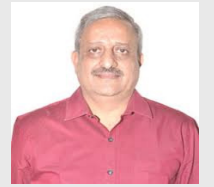

Prof. Dr. Raghuram Rao Akkinepally: Presently working as Director, National Institute of Pharmaceutical Education and Research (NIPER), SAS Nagar, Punjab India. He has more than 30 years of teaching and research experience. Area of interest: Design, synthesis and evaluation of New heterocyclic agents for various pharmacological activities.
\end{abstract}

Cite this article: Akkinepalli RR, Garlapati A, Muthadi S, Mamidi P, Manchinella S, Macha B. Synthesis and Evaluation of New Brominated AzaFlavones and AzaFlavanone Derivatives as Cytotoxic agents against Breast Cancer Cell Line (MCF-7). Indian J of Pharmaceutical Education and Research. 2019;53(1):117-26. 